Section 1280

\title{
Expanding Science and Engineering Outreach Programs Through Cooperation with the Girl Scout Council in El Paso, Texas
}

\author{
Dr. Rebecca L. Dodge, Dr. Andres F. Rodriguez, \\ University of Texas at El Paso/ University of the Pacific
}

\begin{abstract}
In cooperation with the Girl Scout Council in El Paso, Texas, The Pan American Center for Earth and Environmental Studies (PACES) at the University of Texas at El Paso (UTEP) instituted the Summer Science Trek program in the summer of 1996. This program was designed and presented in cooperation with Dr. Andres Rodriguez, an emeritus professor who has developed and offers a similar program at the University of the Pacific in Stockton, California. The goals of the program were to introduce young women to Science and Engineering concepts; to emphasize the importance of Science and Engineering to their everyday life; to present the career options available to them in these fields; to reveal the opportunities careers in these fields offer for contributions to their families and to society; and to make them aware of the academic requirements for such careers. This successful summer program led to an expanded cooperation with the Girl Scout Council. In the 1996 - 97 academic year, PACES participated in the pioneering "In-School Scouting" program in El Paso public schools, presenting science demonstrations and workshops for Scout Troops headed by school teachers in several grade schools. This was followed by participation in a summer "Space Camp" program in the public schools, which is presented by the Girl Scouts as part of the In-School Scouting Program, and by participation in a Scouting program run through local Community Centers. PACES also repeated its successful Summer Science Trek in the Summer of 1997. Participation in these programs over a twelve-month period resulted in contact with over 700 students ranging in grade level from fourth through eighth grade.
\end{abstract}

Summer Science Trek 1996 -97

The initial Summer Science Trek program was designed in consultation with Dr. Andres Rodriguez, with the assistance of PACES Program Coordinator Michelle Smith. Dr. Rodriguez has run a similar, highly successful program at the University of the Pacific in Stockton, California for several years. Through his consulting input and participation in the PACES program, PACES was able to begin an effective outreach effort during its first summer program. The one-week program involved thirty Girl Scouts in hands-on, challenging activities in Physical Sciences, Engineering, and Computer Science. Through the use of simple toys, the students were exposed to the optical, mechanical, and electrical properties of materials. Using simple household items such as straws, beads, and straight pins, students constructed and operated "wind cars." Groups of students also built and launched rockets. Throughout the program, minority University-level Science and Engineering students participated in the projects and demonstrations, serving as successful Science and Engineering role models for the Girl Scouts. These University-level students included both undergraduate and graduate-level women from the Computer Science, Electrical Engineering, and GeoScience Departments. PACES 
Director Dr. Scott Starks and PACES Research Specialist Dr. Brian S. Penn also contributed to the Trek program. Thirty Girl Scouts, as well as several Troop Leaders, participated in the program.

Summer Science Trek 1997 included many of the same activities, and once again was presented by Dr. Rodriguez, with the assistance of Michelle Smith. Approximately thirty Girl Scouts and several Troop Leaders attended. Dr. Rebecca L. Dodge, Research Specialist at PACES, participated in the program, and the content of second Science Trek was expanded to include a rock and mineral identification activity. This activity introduced the scientific method by using properties such as density, specific gravity, hardness, crystal form, color, taste, and smell to identify earth materials. Each student received a rock or mineral sample for which to evaluate physical properties; the students got to keep their samples. All of the rocks and minerals used in the activity were of ores of some economic importance (iron ores, salt, sulfur, graphite, pumice, chalk).

Girls also conducted a "cookie mining" operation, in which each girl is given a sum of money to invest in mining an economic mineral. The activity involves investing in an ore mining property (a chocolate chip cookie); purchase of mining equipment (toothpicks; paper clips); mining the property using the tools (no hands allowed!!), and "restoration" of the property after the mining process is completed (to emphasize the environmental aspects of resource exploitation). Profit or loss is determined by the value of the ore (chips) mined, minus the cost of mining (property purchase, tool purchase, restoration). These new activities increased the students' understanding of the impact of science and engineering on their daily lives, and emphasized the contributions that careers as scientists and engineers will enable them to make to their communities and families.

\section{In-School Scouting 1996 - 97}

This Girl Scout-sponsored program is designed to get minority students involved in Scouting, by providing public school teachers as Troop Leaders in low-income areas where leaders are often difficult to recruit among families. Both girls and boys participate in this program, which becomes part of their regular classroom activities. One day each week is designated as Scouting day, and the class wears uniforms during that day. This program has been very successful in several low-income schools in the El Paso area, offering alternative group activities for at-risk students.

PACES is involved in the In-School Scouting Program at the grade-school level, providing Science and Engineering demonstrations and activities for Scout Troops. The programs are typically conducted in a library setting for several classes at once, with assistance from the teacher/troop leaders. Dr. Dodge, Michelle Smith, Dr. Scott Starks, and several undergraduate Engineering students participated in these presentations, once again modeling participation in University-level Science and Engineering programs. The number of students participating in each presentation was usually about 60, and often the program was conducted for two such groups at each school visited. The total number of students reached at the seven schools visited exceeded 400. Question-and-answer periods followed each presentation, and classes were encouraged to send questions to the PACES staff by mail after the presentations.

Basic science and engineering principles were demonstrated using toys and models, similar to 
those used in the Summer Science Trek program. Students performed simple experiments, both individually and in small groups. Rock and mineral identification activities again included demonstrations and hands-on activities, using samples that the students selected and were allowed to keep.

Mathematical and scientific data collection principles were demonstrated using an inflatable globe that shows the continents, oceans, polar ice caps, and scattered clouds. Students tossed the globe around the classroom 100 times, and recorded the number of times a student's right index finger land on water versus land. Students whose fingers landed on clouds or ice were required to predict what lay under the clouds or ice, with the aid of their fellow students. The percentage of water versus land determined from this sampling procedure was compared to the actual global percentage. This activity demonstrates scientific sampling and analysis procedures, as well as the uncertainties involved in scientific observations.

Space Camp 1997

As part of their In-School Scouting Program, the Girls Scouts sponsored a week-long Space Camp for grade school students in the Ysleta School District in El Paso. This camp provided Science and Mathematics enrichment programs for girls and boys who had participated in the InSchool Scouting Program during the school year, as well as other interested students. PACES conducted a half-day program for over 150 students. The Rocks and Minerals, Cookie Mining, and Land versus Water activities were presented with the help of teachers, Girl Scout outreach staff, Troop Leaders, and PACES staff members Dr. Rebecca L. Dodge and Michelle Smith.

\section{Community Center Program 1997}

In addition to the In-school Scouting outreach effort, The Girl Scouts in El Paso instituted a Community Center-based Scouting program in El Paso in order to provide Scouting opportunities for under-served minority children. Daily enrichment programs are provided for boys and girls during the summer in neighborhood Community Centers. PACES took the Science and Engineering outreach activities to an inner-city Community Center for a half-day program. The Rocks and Minerals, Cookie Mining, and Land versus Water activities were conducted for over 100 grade school and middle school students, with the assistance of Girl Scout outreach staff, Community Center employees, and PACES staff members Dr. Rebecca L. Dodge and Michelle Smith.

\section{Summary and Preliminary Evaluation}

The cooperation between PACES and the Girl Scouts has allowed the PACES Science and Engineering Outreach Program to reach a large number of minority students of both genders. The recruiting function is handled through the Girl Scouts organization, which enables the relatively small staff of PACES to concentrate on developing the Science and Engineering Program. PACES outreach efforts have grown dramatically from the original thirty girls reached during the first summer program, to reach a total of over 700 students during its first year.

PACES will continue to participate with the Girl Scouts in their outreach programs, and will expand these efforts to include Girl Scout Leaders in 1998. PACES will sponsor and participate in a series of workshops designed for Scout Troop Leaders, to be held at UTEP in January. 
PACES will present a workshop on Internet access to 75 Leaders, emphasizing how Girl Scout Troops can use the Internet to find information needed to earn badges. The workshop will be designed for Scout Troop Leaders at all levels of Scouting.

The students who have participated in the program have been exposed to science and engineering principles in a hands-on environment conducive to active participation, innovation, and cooperative learning. Questions and creative solutions have been encouraged during all of the activities. For example, one student in the Summer Science Trek program devised an economic and creative way to handle the cookie mining activity. Instead of buying the two tools normally required to hold the cookie in place while mining the chips (no hands allowed), she bought only one paper clip, and proceeded to unfold it and break it in half to make two tools!

Students involved in the PACES Outreach program have been led to an understanding of the economic and social impacts of Science and Engineering, and have been introduced to career options in these fields. Students have also been provided with positive role models during presentations by minority and women students, scientists, and engineers. In addition to providing enrichment activities for students, the PACES outreach program has introduced teachers to new concepts and techniques for science enrichment. PACES staff are also acting as a continuing mentor source for both students and teachers. Several classes have written followup letters full of new questions, which PACES staff answer in return letters to the teachers. These letters often contain startling admissions. One student proclaimed himself a "science nerd," asking that we please keep it a secret! This provided an opportunity for encouragement and validation for his and others' interest in science and engineering. Other students have consistently expressed surprise and interest in "how important science is." The Science and Engineering undergraduate- and graduate-level UTEP students who have been involved in the PACES outreach program have also benefited from their participation in each of these programs, which has given them the opportunity to teach younger students about their own career choices and fields of interest, to act as role models, and to serve their community.

Acknowledgments

We wish to thank NASA for its support of the project through grant NCW-0089. We also wish to thank the Women in Mining Education Foundation, for developing and encouraging us to use the Cookie Mining activity in our workshops. We extend special thanks to the Girl Scout organization in El Paso Texas for the cooperation and access they have afforded PACES.

\section{Biographies}

DR. REBECCA L. DODGE has a Ph.D. in Geology from Colorado School of Mines (1982). She is employed at the Pan American Center for Earth and Environmental Studies (PACES), a NASA-funded University Research Center at the University of Texas at El Paso, where she coordinates training and outreach programs.

DR. ANDRES RODRIGUEZ is an Emeritus Professor at the University of the Pacific, Stockton, California. He received his D.Sc. degree in Physics in 1955 from Havana University, Cuba. Recipient of numerous teaching awards, including the Alex and Fay Spanos Distinguished Teaching Award, 1979. Author of several books. 